\title{
Biomaterial Based Novel Polyurethane Adhesives for Wood to Wood and Metal to Metal Bonding
}

\author{
Mitesh Ramanlal Patel ${ }^{\text {a*t. }}$, Jignesh Markandray Shukla ${ }^{\text {b**亠 }}$, \\ Natvarbhai Khodidas Patel ${ }^{b}$, Ketan Haribhai Patel \\ ${ }^{a}$ The Polymer Centre, Department of Chemistry, University of Sheffield, \\ Brook hill, Sheffield S3 7HF U.K. \\ ${ }^{\mathrm{b}}$ Department of Chemistry, Sardar Patel University, \\ Vallabh Vidyanagar, 388120 Gujarat, India
}

Received: December 24, 2008; Revised: June 6, 2009

\begin{abstract}
Polyurethane adhesives made from synthetic chemicals are non-biodegradable, costly and difficult to find raw materials from local market. To avoid solid pollution problem, cost effectiveness and easy availability of raw materials, biomaterials based polyurethane adhesives are used in current industrial interest. Direct use of castor oil in polyurethane adhesive gives limited hardness. Modification on active sites of castor oil to utilize double bond of unsaturated fatty acid and carboxyl group yields new modified or activated polyols, which can be utilized for polyurethane adhesive formulation. In view of this, we have synthesized polyurethane adhesives from polyester polyols, castor oil based polyols and epoxy based polyols with Isocyanate adducts based on castor oil and trimethylolpropane. To study the effects of polyurethane adhesive strength (i.e. lap shear strength) on wood-to-wood and metal-to-metal bonding through various types of polyols, cross-linking density, isocyanate adducts and also to compare adhesive strength between wood to wood and metal to metal surface. These polyols and polyurethanes were characterized through GPC, NMR and IR-spectroscopy, gel and surface drying time. Thermal stability of PU adhesives was determined under the effect of cross-linking density (NCO/OH ratio). The NCO/OH ratio (1.5) was optimized for adhesives as the higher $\mathrm{NCO} / \mathrm{OH}$ ratio (2.0) increasing cross-linking density and decreases adhesion. Lower $\mathrm{NCO} / \mathrm{OH}$ ratio (1.0) provideslow cross-linking density and low strength of adhesives.
\end{abstract}

Keywords: adhesive, castor oil, polyurethanes

\section{Introduction}

Generally the adhesives based on polyurethanes used by a wide range of application like woodworking, furniture building/ restoration, boat building/ repair, cabinet making and millwork, stone working, tile and other masonry, light aircraft building/ repair, crafts, and many others. With respect to the different composition and applied methods as well as versatility in polyurethane chemistry, various types of polyurethane adhesives are available in market. Polyurethane adhesives are normally contains a number of urethane group in the molecular backbone or formed during use without consideration of the chemical composition of the chain. So, typical polyurethane adhesive may contain in addition of urethane linkage, aliphatic and aromatic hydrocarbons, esters, ethers, amides, and urea and allophonate linkage, which are responsible to change the final properties ${ }^{1,2}$. Also the performance of adhesives related to its physical properties i.e. viscoelastic and surface free energy, therefore the relationship between composition and properties are great importance ${ }^{3}$. These adhesives are normally consisting of polyols, isocyanates and some compositions of the other materials.

For many years researches have been trying to develop the properties of polyurethane adhesives for different application area via, modification and combination of various polyols as well as isocyanates adducts. Modification in hydroxyl terminated polyols based polyurethane has been studied extensively as they could be effectively used as adhesive $e^{4,5}$. Extensive reports are available on use of polyurethane inter penetrating network (IPN's) and semi inter penetrating network (semi IPN's) as adhesives ${ }^{6-9}$. The developments of environment friendly and high performance polyurethane adhesives for automobiles assemblies have been studied ${ }^{10}$. Polyurethanes adhesive properties also studied under the effects of different kinds of polyether, curing agents and moisture contents on adhesion surface ${ }^{11}$.

*e-mail: drmrp56@ hotmail.com, jignesh.m.shukla@gmail.com

Dr. M.R.Patel is a Postdoctoral Research Scholar in The Polymer Centre, Department of Chemistry, University of Sheffield, Brook Hill, Sheffield, S3 7 HF, South Yorkshire, United Kingdom. He is working on hyper branched polymers for bio-mimic application of artificial blood. He has been working on polyester polyols since 1999.

${ }^{\star}$ Dr. Jignesh Shukla has studied doctorate in Polymer Science at S. P. University, Vallabh Vidyanagar and post-doctorate at University of Sheffield, South Yorkshire, UK. He has worked in Sanmar Specialty Chemicals Ltd., Dadra; TFL Quinn India, Hyderabad; P I Industries, Udaipur and Deepak Nitrite, Nandesari. He is working as a Manager-R\&D in Solvay Advanced Polymer, (Solvay Specialities India Pvt. Ltd.), Panoli.

Dr. K.H.Patel has studied doctorate in Polymer Science at S.P. University, Vallabh Vidyanagar, Gujarat, India. He is working for LGC (Laboratory of Government Chemist) Limited, British Pharmacopoeia Commission Laborator (MHRA), Queens Road, Teddington,, TW11 0LY, U K

Prof. N.K.Patel is working as a Professor in the Department of Chemistry, Sardar Patel University, V.V. Nagar, Anand, Gujarat, India. He has been working on various fields of Polymer Science and Technology for the last 20 years and published many papers in National and International Journals. 
Effects of moisture and temperature on PU adhesives for wood substrate also studied ${ }^{12}$.

The behaviour of a wood and metal adhesive system are depending upon a wide range of variables like surface smoothness of substrates, environment that are related to change in temperature, humanity as well as other physical and application parameters.

The bonding mechanisms of polyurethanes adhesives are different on wood and metal surface. Wood bonding deals with the complex chemistry through celluloid hydrogen bonding i.e. Vander walls forcers, while metal bonding takes a part through the polarity of metal substrate i.e. orientation of polar group. Generally for wood-to-wood bonding urea and phenol formaldehyde based adhesives are available, but some of these are sensitive towards hydrolysis and also cleavage due to stress i.e. normally observed in plywood ${ }^{13-18}$. To strengthen the mechanical properties of plywood, polyurethane adhesives give good results and recently introduced ${ }^{19}$.Some disadvantages such as shorter pot life, durability and higher cost observed in acrylate based adhesives $^{20,21}$.

Polyurethane adhesives made from synthetic chemicals are nonbiodegradable, costly and difficult to find raw materials from local market. To avoid solid pollution problem, cost effectiveness and easy availability of raw materials, biomaterials based polyurethane adhesives are used in current industrial interest ${ }^{22-25}$. Direct use of castor oil in polyurethane adhesive gives limited hardness. Researcher has proposed modification on active sites of castor oil to utilize double bond of unsaturated fatty acid and carboxyl group yields new modified or activated polyols, which can be utilized for polyurethane adhesive formulation. Castor oil based polyurethanes are extensively used in coatings, IPNs, telecommunications, as insulators in electrical industries, foams and adhesives ${ }^{26-30}$. The adhesive properties of polyurethane from modified castor oil or its derivatives are studied under the different variation in composition ${ }^{31-33}$.

In the view of this the present work describe the performance of castor oil based novel polyurethane adhesive system for wood to wood and metal to metal bonding by using polyester polyols, castor oil-polyester polyols and epoxy-polyester polyols with different isocyanate adducts having different $\mathrm{NCO} / \mathrm{OH}$ ratio. The polyester polyols (PO) were synthesized from Adipic acid and ethylene glycol with different stoichiometric proportion. Castor oil-polyester polyols ( $\mathrm{CO}$ ) were synthesized through the transesterification reaction between castor oil and polyester polyols (PO). The epoxy polyester polyols synthesized from Diglycidial ether of bis-phenol A (DGEBA) and polyester polyols under maintain the physical condition. The polyols and polyurethanes adhesives were characterized by FTIR spectroscopy. The adhesive strength (Lapshear strength) of these polyurethanes were measured under the effects of chain length, isocyanate adducts, cross linking density and types of polyols to determine the effects of cross-linking density on thermal stability, gel and surface drying time on polyurethane adhesives.

\section{Experimental}

\subsection{Materials}

Adipic acid and Ethylene glycol were received from SamirTech Chem. P. Ltd. Vadodara, Gujarat, India. Refined castor Oil (Hydroxyl value 165, acid value 0.3) was received from Jayant Oil Mills, Vadodara Gujarat, India. Diglycidial ether of Bisphenol A

Table 1. Physical properties of isocyanate adduct.

\begin{tabular}{ccccc}
\hline Adduct based on TDI & \% of free NCO & $\begin{array}{c}\text { NCO } \\
\text { equivalent }\end{array}$ & $\begin{array}{r}\text { Specific gravity } \\
\text { @ 30 }{ }^{\circ} \mathrm{C}\end{array}$ & $\begin{array}{c}\text { Ford Cup- viscosity } \\
\text { @ 30 }{ }^{\circ} \mathrm{C} \text { by BIV(sec) }\end{array}$ \\
\hline R-60 & 7.48 & 561 & 1.36 & 325 \\
R-90 & 8.0 & 525 & 1.33 & 320 \\
TMP & 12.50 & 336 & 1.02 & 210 \\
\hline
\end{tabular}

Table 2. Characterization Data of polyols.

\begin{tabular}{|c|c|c|c|c|c|}
\hline $\begin{array}{l}\text { Polyols } \\
\text { code }\end{array}$ & Acid value & $\begin{array}{l}\text { Hydroxyl value } \\
\text { (mgKOH/gm) }\end{array}$ & $\begin{array}{l}\text { Hydroxyl } \\
\text { equivalent }\end{array}$ & $\begin{array}{c}\text { Non volatile } \\
\text { content }\end{array}$ & $\begin{array}{c}\text { Brookfield viscosity in Centipoises } \\
\text { @ } 50 \mathrm{rpm} \text { at } 35^{\circ} \mathrm{C} \text { in Spind } \mathrm{n}^{\circ} 1\end{array}$ \\
\hline PO3 & $\approx 0$ & 103 & 545 & 99.5 & 1470 \\
\hline PO4 & $\approx 0$ & 271 & 206 & 99.7 & 176 \\
\hline PO5 & $\approx 0$ & 396 & 141 & 99.3 & 115 \\
\hline $\mathrm{CO} 3$ & - & 128 & 438 & 99.6 & 570 \\
\hline $\mathrm{CO} 4$ & - & 185 & 302 & 99.6 & 324 \\
\hline $\mathrm{CO} 5$ & - & 202 & 276 & 99.4 & 244 \\
\hline EP3 & - & 89 & 627 & 99.2 & 1000 \\
\hline EP4 & - & 186 & 301 & 99.1 & 510 \\
\hline EP5 & - & 239 & 233 & 99.2 & 405 \\
\hline
\end{tabular}<smiles>O=C(CCC(=O)OCO)CCC(=O)OCOC(=O)CCCO</smiles>

Figure 1. Structure of polyester polyol (PO). 
(DGEBA Epoxy equivalent weight - 200) was received from Atul Industries Valsad, Gujarat, India. Triethyl amine and dibutyltindilurate (DBTDL) was obtained from Marck, U.S.A. Isocyanate adducts based on castor oil derivatives (R-90, R-60) received from N.K. Polymers Ahmedabad, Gujarat India and Trimethylol propane based isocyanate adduct received from Grand polycot Padra Gujarat India. These adducts were characterized for their physical properties shown in Table 1.

\subsection{Synthesis of polyols}

\subsubsection{Hydroxyl terminated polyester polyols (PO)}

A mixture of Adipic acid (1 molar) and ethylene glycol (3, 4 and 5 equivalent respectively for $\mathrm{PO} 3, \mathrm{PO} 4$ and $\mathrm{PO} 5$ ) was heated in under the blanket of $\mathrm{N} 2$, in three necked flask equipped with stirrer, thermometer, column and gas inlet initially at $150{ }^{\circ} \mathrm{C}$ and raised up to $230^{\circ} \mathrm{C}$ over the period of 10 hours. The water-glycol azeotrop is continuously removed from the top of the column at $105^{\circ} \mathrm{C}$ and collected in receiver. Finally the by-product water removed was facillated by vacuum. The extent of Polycondensation reaction (esterification) was monitored by acid value determination. The reaction was stopped at the zero acid value, the excess ethylene glycol was distilled out by vacuum distillation and the light yellow product was cooled and the acid value was determined. The hydroxyl value of polyol was determined by acetic anhydridepyridine method ${ }^{34}$. The structure and characterization data of the polyols presented in Figure 1 and Table 2 respectively.

\subsubsection{Castor oil based novel polyols (CO)}

Castor oil based novel polyols were synthesized by the ester exchange reaction of castor oil with polyester polyols. Castor oil (1 molar) and polyester polyol (1 equivalent) derived from Adipic acid and ethylene glycol was charged in three-necked flask equipped with mechanical stirrer, thermometer and reflux condenser. The reaction mixture was heated at $180-200{ }^{\circ} \mathrm{C}$. The completion of reaction was determined by observing separation of resin layer (unreacted

Table 3. Polyurethane adhesives compositions.

\begin{tabular}{|c|c|c|c|}
\hline & $\begin{array}{c}\text { Isocyanate } \\
\text { adduct }\end{array}$ & $\begin{array}{c}\text { Ratio } \\
\mathrm{NCO} / \mathrm{OH}\end{array}$ & $\begin{array}{c}\text { Amount of adduct in gms } \\
\text { @ } 5 \text { gm of polyol }\end{array}$ \\
\hline $\mathrm{PO} 3$ & R-90 & 1.0 & 04.80 \\
\hline PO4 & R-90 & 1.0 & 12.74 \\
\hline PO5 & R-90 & 1.0 & 18.52 \\
\hline PO3 & R-90 & 1.5 & 07.20 \\
\hline PO3 & R-90 & 2.0 & 09.50 \\
\hline $\mathrm{CO} 3$ & R-90 & 1.0 & 05.90 \\
\hline $\mathrm{CO} 4$ & R-90 & 1.0 & 08.60 \\
\hline $\mathrm{CO} 5$ & R-90 & 1.0 & 09.45 \\
\hline $\mathrm{CO} 4$ & R-60 & 1.0 & 09.25 \\
\hline $\mathrm{CO} 4$ & TMP & 1.0 & 05.50 \\
\hline EP3 & R-90 & 1.0 & 04.15 \\
\hline EP4 & R-90 & 1.0 & 08.70 \\
\hline EP5 & R-90 & 1.0 & 11.18 \\
\hline EP5 & R-60 & 1.0 & 12.00 \\
\hline EP5 & TMP & 1.0 & 07.15 \\
\hline
\end{tabular}<smiles>[R]C(=O)OCC(CO)OC(=O)CC(=O)OCOC(=O)COC(=O)CCC(=O)OCO</smiles>

Where, $\mathrm{R}=$ $\left(\mathrm{H}_{2} \mathrm{C}\right.$ $\mathrm{CH}=$<smiles></smiles>

Figure 2. Structure of castor oil-polyester polyol (CO) (Mixture). 
<smiles>[R]OOCC(O)Oc1ccc(C(C)(C)c2ccc(OC(O)COO)cc2)cc1</smiles><smiles>[R]CNOC(=O)CCC(=O)OCC[Hg]C(=O)CCC(=O)OCC</smiles>

Figure 3. Structure of epoxy-polyester polyols (EP).

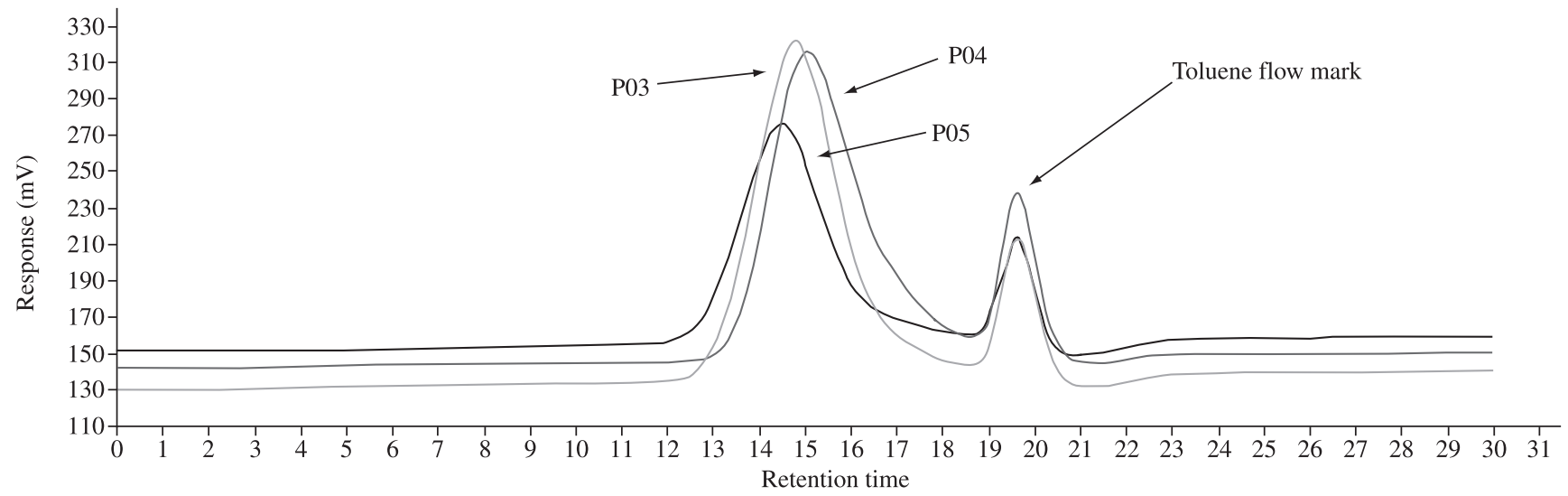

Figure 4. GPC of polyols.

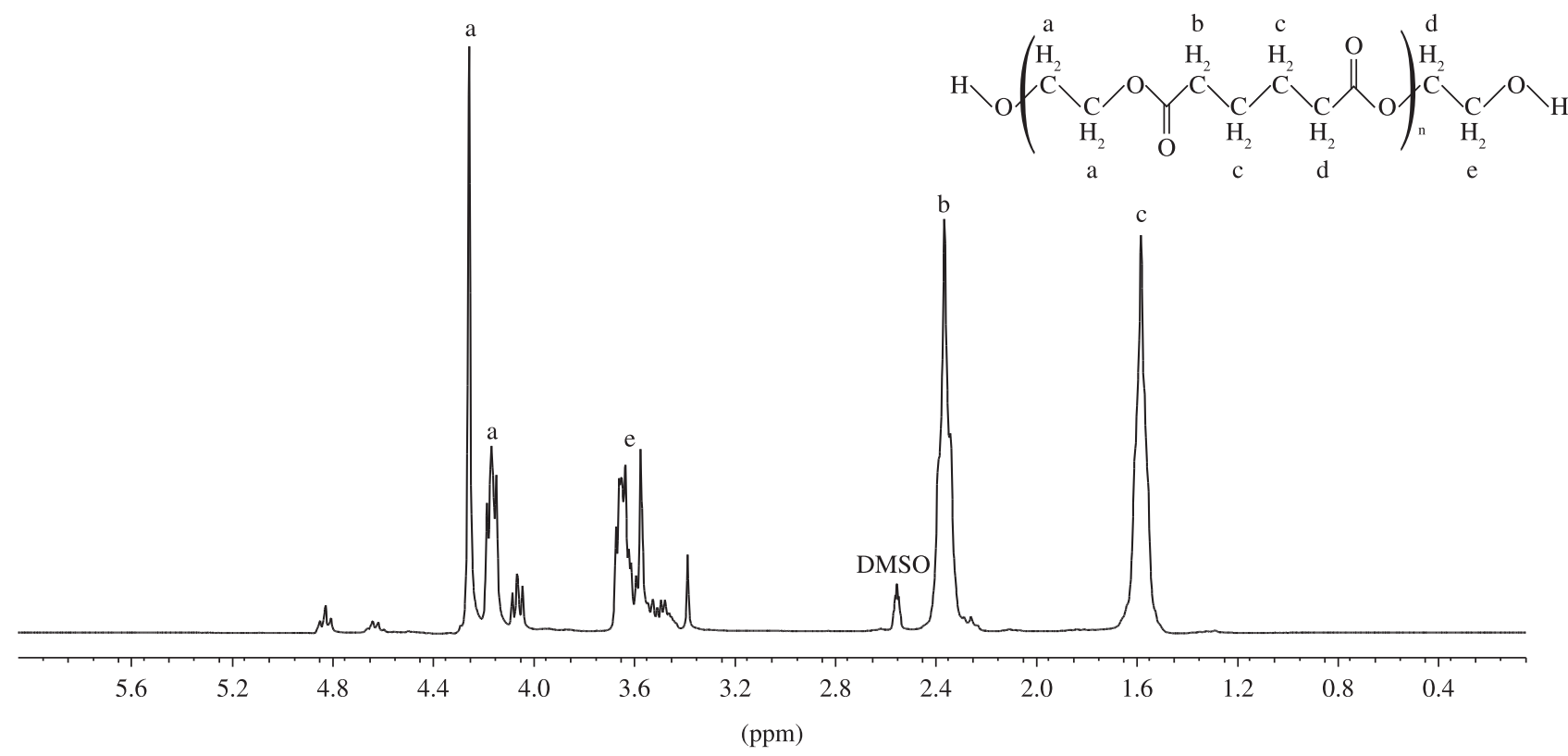

Figure 5. NMR spectra of polyol PO3. 
polyol). It was observed that the reaction took $\sim 9$ hours. Therefore all ester exchange reaction was carried out for 10 hours. At the end of the reaction hydroxyl value of the product was determined ${ }^{34}$. The structure and characterization data of the polyols presented in Figure 2 and Table 2 respectively.

\subsubsection{Epoxy based novel polyols (EP)}

Novel epoxy based polyols were synthesized from Diglycidial ether of bis phenol A (1 molar) and polyester polyols (PO) derived (2 equivalent) were charged in the three necked flask containing $25 \mathrm{~mL}$ dioxane equipped with nitrogen inlet and water condenser along with 0.05 mole of triethyl amine catalyst, the reaction was reflux for 3 hours. Determining the epoxy equivalent weight monitored the extent of the reaction. The infinite value of epoxy equivalent indicates completion of the reaction. After the completion of the reaction dioxane was recovered by vacuum distillation and viscous liquid as epoxy based polyols free from dioxane was collected in clean glass stopper bottle. Hydroxyl value of the product was determined ${ }^{34}$. The reaction scheme and characterization data of the polyols presented in Figure 3 and Table 2 respectively.

Note: All epoxy based polyols having zero epoxy equivalent value.

\subsubsection{Polyurethane adhesive preparation}

Preparation of adhesives were carried out by reacting polyols with different Isocyanate adducts having different $\mathrm{NCO} / \mathrm{OH}$ ratio, along

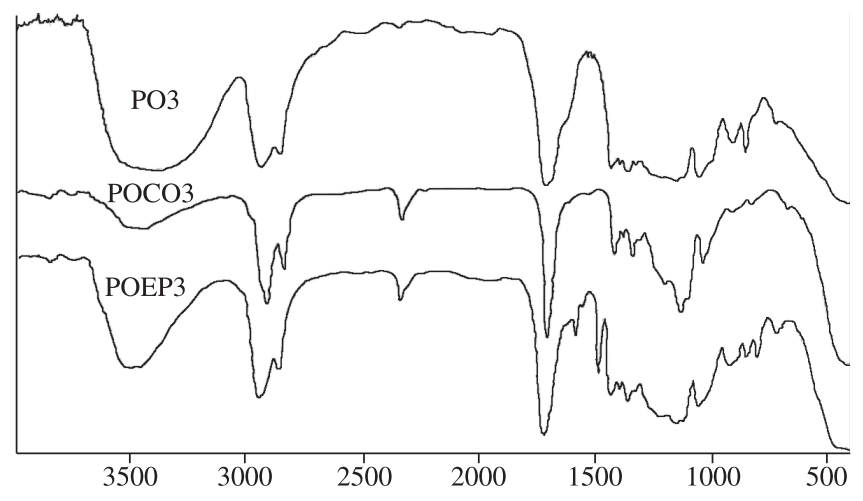

Figure 6. IR spectra of polyols.

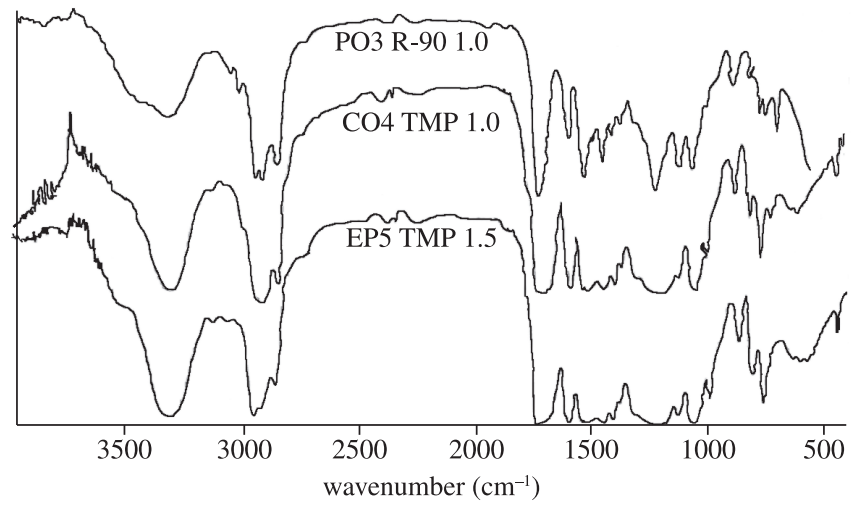

Figure 7. IR spectra of polyurethane. with DBTDL ( $0.05 \%$ w.w $\mathrm{w}^{-1}$ of total composition). The compositions of different polyurethane adhesives studied in this work are shown in table 3 . The adhesives were diluted by MEK to give an appropriate viscosity for effect application on wood and metal substrate.

\subsubsection{Wood and metal specimen preparation}

Teak wood has been relied upon and trusted for its uncommon strength. This wood is highly prized by lovers and collectors of furniture the world over. The reputation of Teak throughout the whole world in producing furniture of the highest quality has, however, never faltered. As per test sample requirement teak wood pieces (longitudinal) were cut into $300 \times 25 \times 3 \mathrm{~mm}^{3}$ strips and polished using sand paper grit number $60(250 \mu \mathrm{m})$ the metal were cut into $203 \times 25 \times 1.62 \mathrm{~mm}^{3}$ strips and dried (at $100{ }^{\circ} \mathrm{C}$ for 15 minutes in oven) to make it moisture free and after drying they were polished using sandpaper grit number $60(250 \mu \mathrm{m})$.

\subsubsection{Bonding and testing (for wood and metal)}

Using a brush the adhesive solution was applied on both the pieces of the substrate for a thickness of $0.1 \mathrm{~mm}$ and lap joined giving $25 \times 30 \mathrm{~mm}^{2}$ for wood strips and $25 \times 25 \mathrm{~mm}^{2}$ for metal strips area of overlap. Load $(2.5 \mathrm{~kg})$ was placed over the contact points of wood and metal peaces and left overnight. After that the joints were kept at room temperature $\left(30{ }^{\circ} \mathrm{C}\right)$ and at relative humidity of $50 \pm 5 \%$ for seven days. Each joint specimen was tested for the lap-

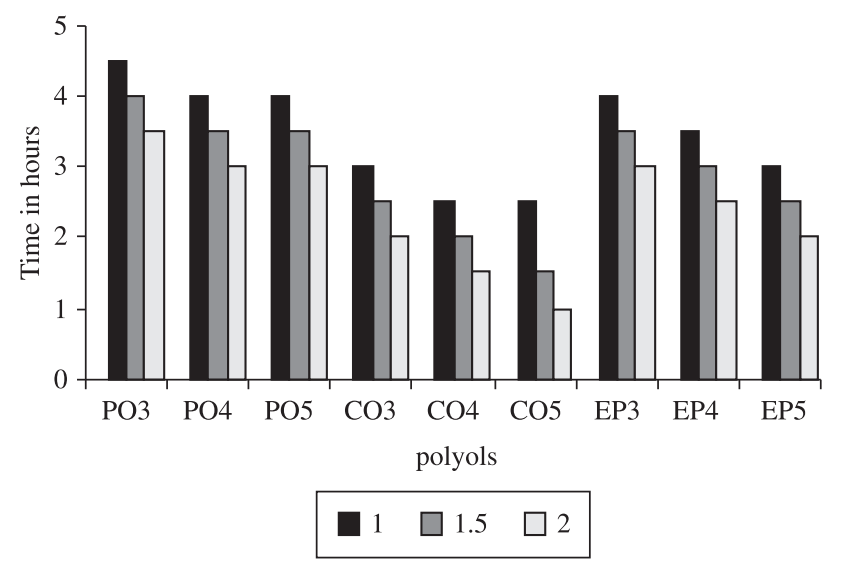

Figure 8. Gel times of PU'S at different $\mathrm{NCO} / \mathrm{OH}$ ratio.

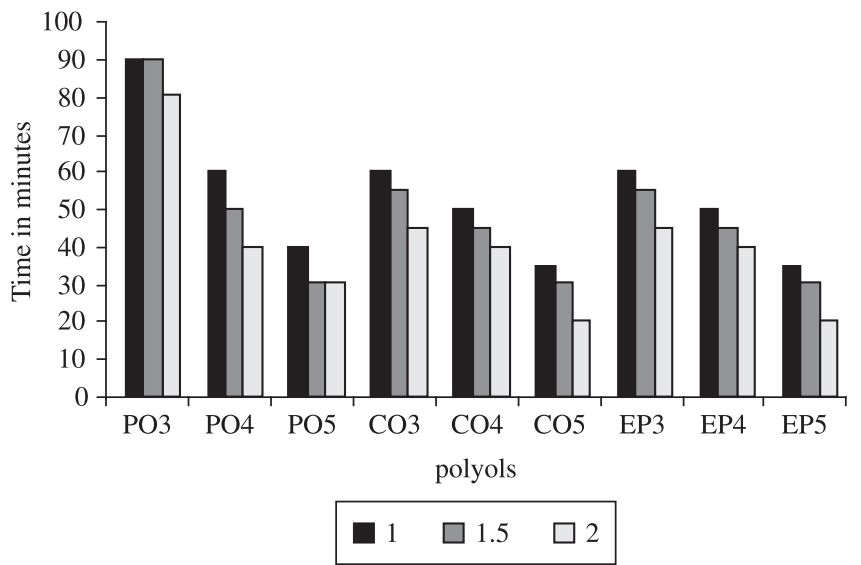

Figure 9. Surface drying of PU'S at different $\mathrm{NCO} / \mathrm{OH}$ ratio. 
shear strength using a Zwick UTM model 1445 according to ASTM D 906-82 (1987).

\subsubsection{Thermogravimetry}

Thermogravimetry analysis (TGA) was performed under air from 30 to $800{ }^{\circ} \mathrm{C}$, at a heating rate of $10^{\circ} \mathrm{C} /$ minute on Shimadzu Thermal (DT-30B) Analyzer.

\section{Results and Discussion}

\subsection{Characterization through GPC (SEC), NMR and IR spectroscopy}

Polyols were characterized by GPC, NMR and IR spectroscopy as shown in Figure 4, 5 and 6 . The band at about $3400 \mathrm{~cm}^{-1}$ is due to $-\mathrm{OH}$ stretching of all the polyols. The strong and broad band indicates presence of the hydroxyl group associate to polymeric compound. The bands at about 1050 and $1350 \mathrm{~cm}^{-1}$ indicate the

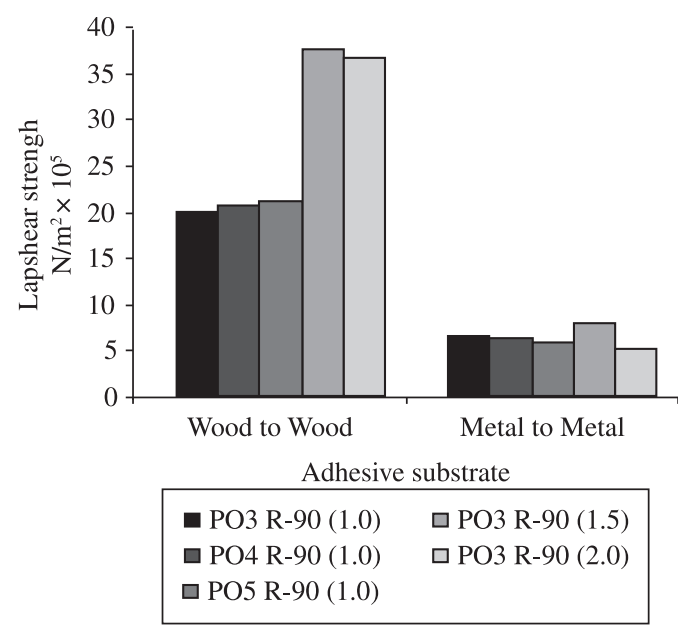

Figure 10. Effects of chain length of polyester polyols (PO3, PO4 and PO5) and cross linking density $(\mathrm{NCO} / \mathrm{OH})$ on PU's adhesion strength.

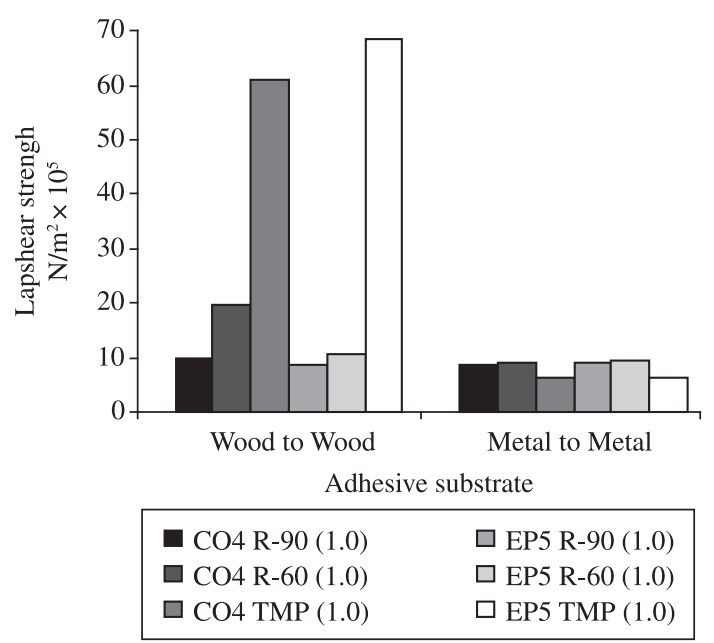

Figure 11. Effects of types of adducts (R-90, R-60 and TMP) on PU's adhesion strength.
$\mathrm{O}-\mathrm{H}$ banding of primary alcohol and C-O stretching of ester group respectively. The very strong band in the range of $1750-1735 \mathrm{~cm}^{-1}$ shows $\mathrm{C}=\mathrm{O}$ stretching of aliphatic ester. The bands are not observed in between $1770-1750 \mathrm{~cm}^{-1}$ clearly indicates the absence of aliphatic acid in PO3 i.e. polyester having zero acid value. The bands of C-H stretching and bending (deformation) in the $-\mathrm{CH} 2$ group are observed at about $2962-2853 \mathrm{~cm}^{-1}$ and $1485-1445 \mathrm{~cm}^{-1}$ respectively.

The bands are not observed at about $920 \mathrm{~cm}^{-1}$ clearly indicates that there are no terminal epoxy group present in novel polyols EP3 but they are reacts with -OH group of polyester polyols and the oxirine ring of epoxy group is converted in the form of secondary alcoholic group of novel polyols which is conformed at about $1100 \mathrm{~cm}^{-1}$ of $-\mathrm{OH}$ banding in secondary alcohol. The band at about $1650-1500$ and $1220-1020 \mathrm{~cm}^{-1}$ indicates N-H banding vibration and $\mathrm{C}-\mathrm{N}$ vibration respectively of amine catalyst used in EP3 polyols synthesis.

IR spectra of Polyurethane showed in Figure 7. The bands at about $3330 \mathrm{~cm}^{-1}$ and about $1560-1650 \mathrm{~cm}^{-1}$ indicates that the $\mathrm{N}-\mathrm{H}$ stretching and $\mathrm{N}-\mathrm{H}$ bending of urethane group. The bands observed in between $2962-2853 \mathrm{~cm}^{-1}$ indicates the $\mathrm{C}-\mathrm{H}$ stretching and $\mathrm{C}-\mathrm{H}$ bending of alkane the bands at $1220-1020$ and $1410 \mathrm{~cm}^{-1}$ is the $\mathrm{C}-\mathrm{N}$ vibration in urethane group. The band in between $1740-1690 \mathrm{~cm}^{-1}$ indicates clearly that the formation of urethane group. The frequency about the $870 \mathrm{~cm}^{-1}$ presents the substituted aromatic ring of TDI.

\subsection{Gel and surface drying time}

The gel and drying time measured for PU'S from the polyester polyols, castor oil based polyols, epoxy based polyols with R-90 based TDI adduct in different proportions to have different $\mathrm{NCO} / \mathrm{OH}$ ratio.

The results in Figure 8 clearly indicate that the gel time decreases as the $\mathrm{NCO} / \mathrm{OH}$ ratio increases for all the sets. This is because of the higher reactivity of $\mathrm{NCO}$ group i.e. as the - $\mathrm{NCO}$ content increase reactivity towards $-\mathrm{OH}$ group required for cross linking increases. The increased reactivity with $\mathrm{NCO}$ content is highest with $2.0 \mathrm{NCO} /$ $\mathrm{OH}$ in all the cases.

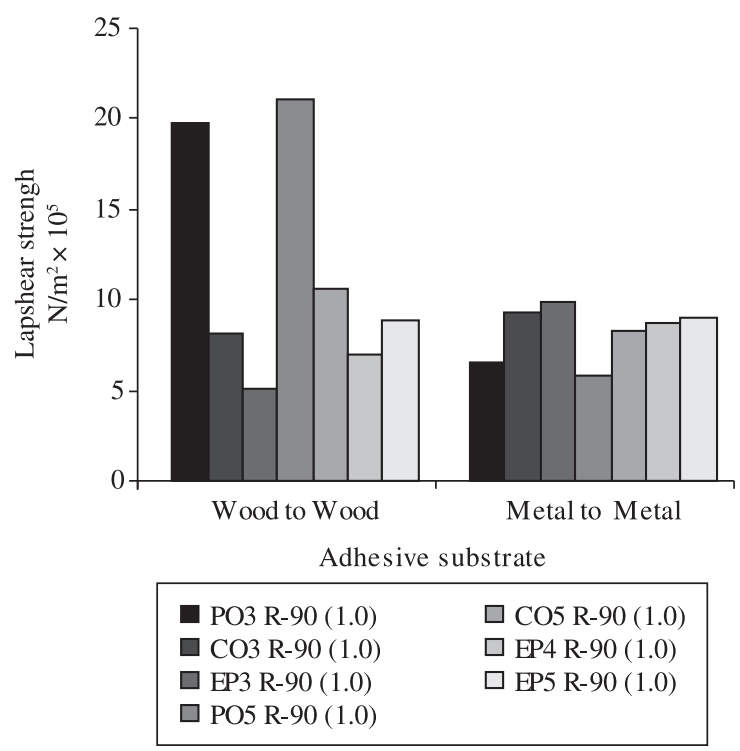

Figure 12. Effects of types of polyols (Polyester, castor oil and Epoxy based) on PU's adhesion strength. 
Time of Surface drying for the same sets of polyurethane are also reported in the Figure 9. The observation of data indicates that:

- The castor oil polyols based and epoxy polyols based polyurethanes shows lower times for drying.

- Polyester polyols based polyurethanes took more time for drying.

In above trend the hydroxyl group of castor oil is activated by its combination with polyester polyols and as the hydroxyl functionality is more then two, the cross linking reaction is faster as a result of which polyurethanes based on these polyols shows faster drying.

In the case of epoxy based polyester polyols is having higher hydroxyl functionality increases its reactivity while a bulky bis-phenol group hindered mobility and hence decreases reactivity. These two opposite effects ultimately balance the reactivity of hydroxyl groups towards Isocyanate and hence drying time of polyurethane is in the range of castor oil based polyols.

Low reactivity of polyester polyols is known and hence shows highest drying time.

\subsection{Adhesive strength}

Lap shear strength of different polyurethanes on wood-wood and metal-metal substrate (10 pcs.) analysed under the effects of chain length of polyols, cross linking density, types of polyols and Isocyanate adducts shown in Figure 10, 11 and 12.

\subsubsection{Effects of chain length and cross linking density $(\mathrm{NCO} / \mathrm{OH})$}

The adhesive strength in PU prepared from shorter polyols (PO5) shows higher degree of adhesion then PU prepared from higher chain length polyols (PO3) on wood substrate. As length between two-cross linking point's decreases, flexibility decrease, the possibility of orientation of ester group towards substrate decreases. This in turn decreases the possibility of interaction between hydrogen group of substrate and ester linkage of polyurethane.

There fore actually for polyol of higher length should show higher adhesion. But on other hand the concentration of urethane linkage is more with PO5 polyurethanes (shorter chain), which increases the possibility of hydrogen-bond formation between adhesive and substrate, and it is predominant. Thus the adhesion is more in PO5 polyurethanes compare to $\mathrm{PO} 4$ and $\mathrm{PO} 3$ polyurethanes.

In case of metals interaction is through polarity and not through hydrogen bonding, therefore the ester linkage interaction is much more important in metal compare to wood. The interaction of ester group of polyurethane with metal substrate will be more in PO3 due to more number of ester groups and higher flexibility, provides higher orientation of ester group towards substrate in PO3. Therefore the adhesion tends of polyurethane metal system is exactly reverse then that of polyurethane wood systems.

With increasing in $\mathrm{NCO} / \mathrm{OH}$ ratio strength of adhesive also increases. This is responsible for higher cross-linking density to improve adhesion property. But after certain limit $(\mathrm{NCO} / \mathrm{OH}=1.5)$ much more cross-linking hindered the orientation of ester groups decreases the flexibility. Therefore adhesion properties decrease after critical value. After critical value the rigidity increases, imposed by higher concentration of NCO hindered orientation possibility required for optimum interaction between substrate and adhesive decreases, therefore beyond critical value of $\mathrm{NCO} / \mathrm{OH}$ ratio adhesion decreases rather than increases.

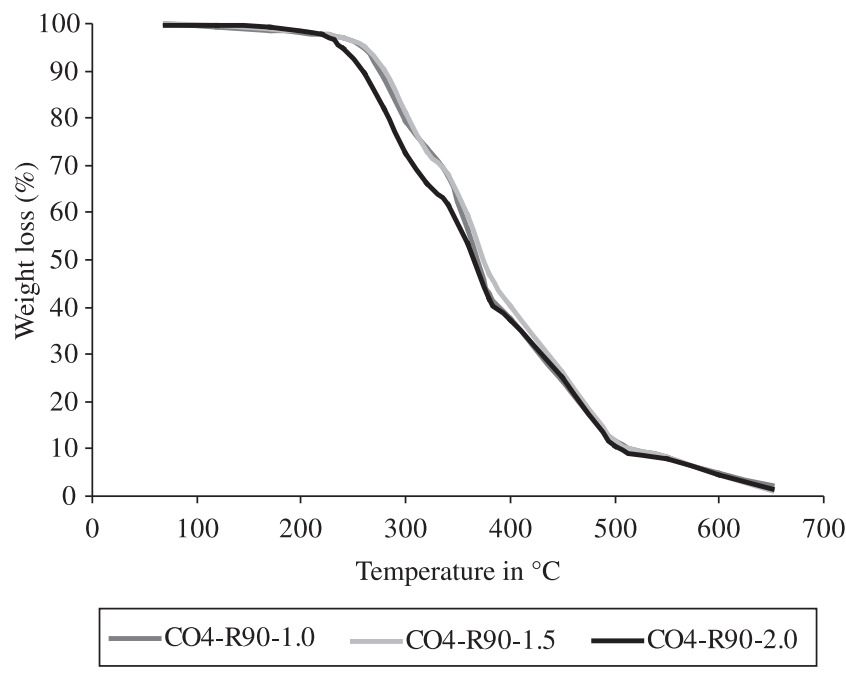

Figure 13. Thermogram of polyurethane adhesives

Table 4. Activation energy of polyurethane adhesives:

\begin{tabular}{ccc}
\hline Polyurethanes & IDT & Ea $(\mathrm{kJ} / \mathrm{mol})$ \\
\hline CO4 R-90 1.0 & 354 & 39.54 \\
CO4 R-90 1.5 & 362 & 40.64 \\
CO4 R-90 2.0 & 346 & 38.95 \\
\hline
\end{tabular}

\subsubsection{An effect of isocyanate adducts}

The results of wood-wood polyurethane adhesive elaborate that the Isocyanate adducts are also play an important role for adhesive strength.

Trimethylol propane based isocyanate adducts, castor oil based R-90 and R-60 adducts reacts with polyol in which Trimethylol propane adducts have higher strength compare to R-90 and R-60 adducts on wood. Higher reactivity and rigidity of TMP compare to castor oil based R-90 and R-60 which is responsible to improve the strength of adhesion.

\subsubsection{Effects of types of polyols}

In case of metal-to-metal bonding the excellent adhesion strength is obtained in epoxy based polyol compare to polyester and castor oil based polyols. Aromatic nature of epoxy based polyol shows higher adhesive strength due to Electronic resonating cloud of Bisphenol-A moiety, Higher cross linking density compare to polyesterpolyol and Higher strength of adhesive film compare to castor oil based polyol.

The reverse phenomenon observed in wood to wood adhesive because of decreasing in cross linking density as well as increasing in flexibility to provide the orientation of groups for H-bonding formation with substrate.

Compare to polyester-polyol, castor oil based polyol are more flexible. Orientation of ester groups as well as higher cross-linking density in castor oil based polyol compare to linear polyester polyol, which is responsible for formation of hydrogen bonding with substrate as well as increase in adhesive strength. The sufficient functionality in epoxy based polyols to cross linking but the arometicity of bis'phenol A moiety to hindered the orientation of the group towards substrate so the polyurethanes based on epoxy polyols having lower adhesion strength compare to castor oil polyols as well as polyester polyols on wood substrate. 


\section{Thermal Analysis}

The effects of cross-linking density on thermal stability of castor oil based polyurethane adhesives were studied. Thermo grams indicate that the negligible weight loss up to $240{ }^{\circ} \mathrm{C}$ i.e. the polyurethanes are stable up to $240{ }^{\circ} \mathrm{C}$ with irrespective of crosslinking density ( $\mathrm{NCO} / \mathrm{OH}$ ratio) which shown in Figure 13.

The polyurethanes degraded not well-distinguished two stages. The degradation in the first stage of polyurethanes may correspond to the breaking of urethane bond and leading the formation of carbon dioxide, alcohols, amines carbon monoxide etc. ${ }^{35-36}$. In the second stage at about $350{ }^{\circ} \mathrm{C}$ may be due to the decomposition of ether and ester links. Castor oil based polyols and castor oil based adduct, the main chain degradation may occur with the formation of 10 undecanoic acid and heptenal as evidenced by the thermal degradation of recenoleic acid ${ }^{37}$.

The decomposition activation energy of these polymers was evacuated using the well-known Broido's method (Table 4) ${ }^{38}$.

The activation energy of the polyurethanes having $1.5 \mathrm{NCO} / \mathrm{OH}$ shows higher value. It indicates that the thermal stability increases with increasing $\mathrm{NCO} / \mathrm{OH}$ ratio up to certain limit. Above the certain limit a high cross-linked structure of polyurethanes having more number of urethane linkages provides less energy to degradation.

\section{Conclusion}

Adhesives were prepared from different polyols with different isocyanate adducts. The $\mathrm{NCO} / \mathrm{OH}$ ratio (1.5) was optimized for adhesives as the higher $\mathrm{NCO} / \mathrm{OH}$ ratio (2.0) increasing cross-linking density and decreases adhesion. Lower $\mathrm{NCO} / \mathrm{OH}$ ratio (1.0) provides low cross-linking density and low strength of adhesives.

- Gel time decreases as the $\mathrm{NCO} / \mathrm{OH}$ ratio increases in all the cases;

- Low reactivity of polyester polyols shows highest surface drying time;

- Adhesion on wood through hydrogen bonds and on metal substrate through polarity showed reverse trends for polyurethane adhesives for wood and polyurethane adhesives for metal;

- Adhesive strength of shorter chain length polyols (PO5) has higher value for wood and lower for metal substrate;

- The adhesive based on TMP adducts gave the higher value of adhesion for wood compare castor oil based R-90 and R-60 adducts;

- The Caster oil polyol with TMP adduct based adhesive provided good adhesive strength compare to epoxy polyols with TMP adduct based adhesive, as flexibility of long chain presence in castor oil polyols;

- Polyester polyols with R-90 based adhesives shown higher adhesive strength for wood compare to castor oil polyols and epoxy polyols with R-90 adducts; and

- Adhesive based on castor oil polyol and epoxy polyols with R-90 adducts shown lower adhesive strength due to high crosslinking density and rigidity respectively.

\section{References}

1. Eling B and Phanopolous C. Polyurethane adhesives and binders. Kortenberg; 2003. Available from: <http://www.huntsman.com/pu/Media/ Loughborough.pdf>.

2. Strobech C. Polyurethane adhesives. International Journal of Adhesive \& Adhesion. 1990; 10(3):225-228.

3. Krenceski MA, Johnson JF and Temin SC. Chemical and Physical factors affecting performance of pressure-sensitive adhesives. Polymer Reviews. 1986; 26(1):143 - 182
4. Liang F and Dreyfuss P. Durability of adhesive bonds between glass or metal substrates and a polybutadiene-polyurethane. Journal of Applied Polymer Science. 1984; 29(10):3147 -3159.

5. Kimball ME. Polyurethane Adhesives: Properties and Bonding Procedures Adhesives Age. 1981: 21.

6. Takemura A and Mizumaehi H. Advances in Interpenetrating Polymer Networks. Lancaster, PA: Technomic Publishing Co.; 1991. p. 25.

7. Jia D, Pang Y and Liang X. Mechanism of adhesion of polyurethane/ polymethacrylate simultaneous interpenetrating networks adhesives to polymer substrates. Journal of Polymer Science Part B: Polymer Physics. 32(5):817-823.

8. Yenwo GM, Manson JA, Pulido J and Sperling LH. Castor-oil-based interpenetrating polymer networks: Synthesis and characterization. Journal of Applied Polymer Science. 1977; 21(6):1531-1541.

9. Devia N, Manson JA, Sperling LH and Conde A. Simultaneous interpenetrating networks based on castor oil elastomers and polystyrene 2. Synthesis and systems characteristics. Macromolecules. 1979; 12:360.

10. Oertel G (Ed.). Polyurethane Handbook. New York: Hansher Publishers; 1985. p. 54

11. Benli S, Yilmazer U, Pekel F and Ozkar S. Effect of fillers on thermal and mechanical properties of polyurethane elastome. Journal of Applied Polymer Science. 1998; 68(7):1057-1065.

12. Badri KH, Ujar AH, Othman Z and Sahaldin FH. Shear strength of wood to wood adhesive based on palm kernel oil. Journal of Applied Polymer Science. 2006; 100(3):1759-1764.

13. White JT. Market trends for wood adhesives. Adhesives Age. 1981; $7: 19$.

14. Myres GE. New technologies and materials for bonding wood products. Adhesives Age. 1988; 31(11): 31-36.

15. Freeman GG and Krebich S. Estimating durability of wood adhesives in vitro. Forest Products Journal. 1968; 18:39.

16. Ebewele RO, River BH and Myres GE, Failure mechanisms in wood joints bonded with urea-formaldehyde adhesives. European Journal of Wood and Wood Products. 1994; 52(3):179-184.

17. Tranghton GE and Chow S. Accelerated Aging of Glue-Wood Bonds. Journal of the Institute of Wood Science. 1968; 21:29.

18. Dinwoodie JM. The properties and performance of particleboard adhesives. Journal of the Institute of Wood Science. 1978; 8:59.

19. Dias FM and Lahr FAR. Alternative castor oil-based polyurethane adhesive used in the production of plywood. Materials Research. 2004; 7(3):413-420

20. Vallat MF and Bessaha B. Adhesive behavior of polyurethane-based materials. Journal Applied Polymer Science. 2000; 76(5):665-671.

21. Jia D and Liang X. Mechanism of adhesion of polyurethane/ polymethacrylate simultaneous interpenetrating networks adhesives to polymer substrates. Journal of Polymer Science, Part B: Polymer Physics. 1994; (132):817.

22. Dunky M. Handbook of Adhesive Technology. Pizzi A and Mittal KL (Eds.). New York, NY, USA: CRC Press; 2003. p. 887-956.

23. Petrovic ZS and Javni IJ. US Patent 6399698, June 4, 2002.

24. Desai SD, Patel JV and Sinha VK. Polyurethane adhesive system from biomaterial-based polyol for bonding wood. International Journal of Adhesion and Adhesives. 2003; 23(5): 393-399.

25. Desai SD, Emanuel AL and Sinha V. Biomaterial Based Polyurethane Adhesive for Bonding Rubber and Wood Joints. Journal of Polymer Research. 2003; 10(4):275-281.

26. Patel N, Kansara S, Somani K and Raxit A. Polyol from castor oil and epoxy resin for PU coatings. European Coating Journal. 2003; 11:34-40.

27. Athawale VD and Kolekar SL. Comparative studies of castor and hydrogenated castor oil urethane/pmma semi and full IPNs. Journal of Macromolecular Science A: Pure and Applied Chemistry A. 1998; 35(12):1929-1940. 
28. Dias FM and Lahr FAR. Alternative castor oil based polyurethane adhesive used in the production of plywood. Materials Research. 2004; 7(3):413-420.

29. Patel $P$ and Suthar B, Interpenetrating polymer networks based on castor oil, XVIII, Journal of Applied Polymer Science 1990; 40:1037.

30. Altafim RAC, Murakami CR, Araujo LCR, Neto SC and Chierice GO. Polyurethane resins derived from castor oil for the fabrication of polymeric. In Proceedings of Annual Report - Conference on Electrical Insulation and Dielectric Phenomena; 1999; Austin. IEEE. p. 305-308.

31. Sanmathi CS, Prasannakumar S and Sherigar BS. Interpenetrating polymer networks based on polyol modified castor oil polyurethane and poly(2-ethoxyethyl methacrylate): Synthesis, chemical, mechanical, thermal properties, and morphology. Journal of Applied Polymer Science. 2004; 94(3):1029-1034.
32. Somani KP, Kansara SS, Patel NK and Rakshit AK. Castor oil based polyurethane adhesives for wood-wood bonding. International Journal of Adhesion and Adhesives. 2003; 23(4):269-275.

33. Liu Y, Zong MCZ and Xu Y. Manufacturing of the self-crosslinking PVAc emulsion under room temperature. Zhongguo Jiaonianji. 2005 14(7):9-11.

34. Cocks IV and Vanredew C. Laboratory hand book for oil and fat analysis. London: Academic Press; 1976.

35. Jellinek HHG and Dankle SR. Degradation and stability of polymers. London: Elsevier Publication; 1983. p. 91

36. David DJ and Staley MP. Analytical chemistry of polyurethane. New York: Wiley Intersicence; 1974. p. 365

37. Saunders JH and Frisch KC. Polyurethane chemistry and technology. New York: Interscience; 1963. p. 51.

38. Broido A. Simple, sensitive graphical method of treating thermogravimetric analysis data. Journal Polymer Science A. 1969; 7:1761. 